\title{
Abdominal Pregnancy Case Report and Review of the Literature
}

\author{
Major A M McCullough \\ MB MRCOG RAMC \\ Senior Specialist Dept of Ubstetrics and Gynaecology Cambridge Military Hospital Aldershot
}

\section{Introduction}

An unusual case of ectopic pregnancy resulting in a secondary abdominal pregnancy is presented. Discussion of the case and review of the literature follows.

\section{Case Report}

A 41 year old widow with four children was admitted as an emergency with an acute exacerbation of pain referred to the pelvis and rectum from which she had suffered intermittently for about three weeks. She also complained of one week's unpleasant brown vaginal discharge.

The menstrual cycle had been normal until three months previously when she had some irregular vaginal bleeding. Her last normal period was 10 weeks previously but approximately two weeks before she had had a day's vaginal bleeding associated with colicky pelvic pain. This had settled by the following day and she thought no more of it.

The patient took no contraceptive measures and admitted to unprotected sexual intercourse some 2-3 months previously. On examination she was obviously in pain. She had peritonism, cervical excitatory pain, a brown vaginal discharge and a mass in the Pouch of Douglas. From a cardiovascular point of view she was in a stable condition.

In view of the presence of the pelvic mass a laparotomy rather than laparoscopy was considered necessary to make a firm diagnosis.

At laparotomy a live pregnancy measuring $5.7 \mathrm{~cm}$ CRL was found in the Pouch of Douglas (Fig 1) amongst clot and trophoblastic tissue loosely attached to peritoneum and ovary. The right fallopian tube was ruptured in the mid isthmus and was filled with clot. There was slight fresh bleeding from the edges of the rupture. The Pouch of Douglas was swept clean and a right salpingectomy was performed. No obvious trophoblastic tissue was left in the pelvis. Dilatation and curettage was also performcd.

Pathological examination confirmed decidual change at the site of pregnancy; while mesothelial proliferation and organisation of blood clot at the site of rupture suggested that tubal rupture had taken place about seven days previously.

The patient made a satisfactory and rapid post- operative recovery and was discharged six days later.

Urinary Human Chorionic Gonadotrophin assay four weeks later was negative. At six week post-operative review all was well and she was discharged from hospital care.

\section{Discussion}

This case illustrates a fairly classical presentation of ectopic pregnancy. The period of amenorrhoea was rather longer than one usually sees, and the pregnancy more advanced suggesting that inevitable abortion may have been a possible diagnosis. Pregnancy in a rudimentory horn, severe pelvic inflammatory disease, ovarian cyst complications and appendix mass were also possibilities.

Although further investigation such as pelvic ultrasound and pregnancy testing may have helped exclude some of the differential diagnoses, the clinical picture and findings warranted exploratory laparotomy.

The finding of a secondary abdominal pregnancy is rare and this appeared clinically, and subsequently pathologically, to be well established.

The acute presentation at this time was presumably due to additional haemorrhage either from the site of tubal rupture or the site of secondary implantation. Had this not occurred it is quite feasible that this pregnancy could have become much more advanced.

\section{Review of the Literature}

Some 120 years before Robert Lawson Tait established the importance of laparotomy and excision for ectopic pregnancy, John Bard of New York operated for extrauterine pregnancy, following consultation with the Army Surgeon Dr Huck who correctly made the diagnosis. The gestation is not recorded but a macerated fetus and considerable pus was found. No placenta was found and the wound, treated by the open method, had healed some 10 weeks later. When one appreciates that there was no anaesthesia and mortality from abdominal surgery was extremely high in 1759 this is a noteworthy occurrence. Advanced extrauterine pregnancy had been described in the 10th Century by Albucasin but the first recorded case was the wife of Jacob Nufer in 1500 when both mother and child survived ${ }^{2}$. The first genuine case of primary abdominal pregnancy is credited to Galbin $(1896)^{3}$. The 


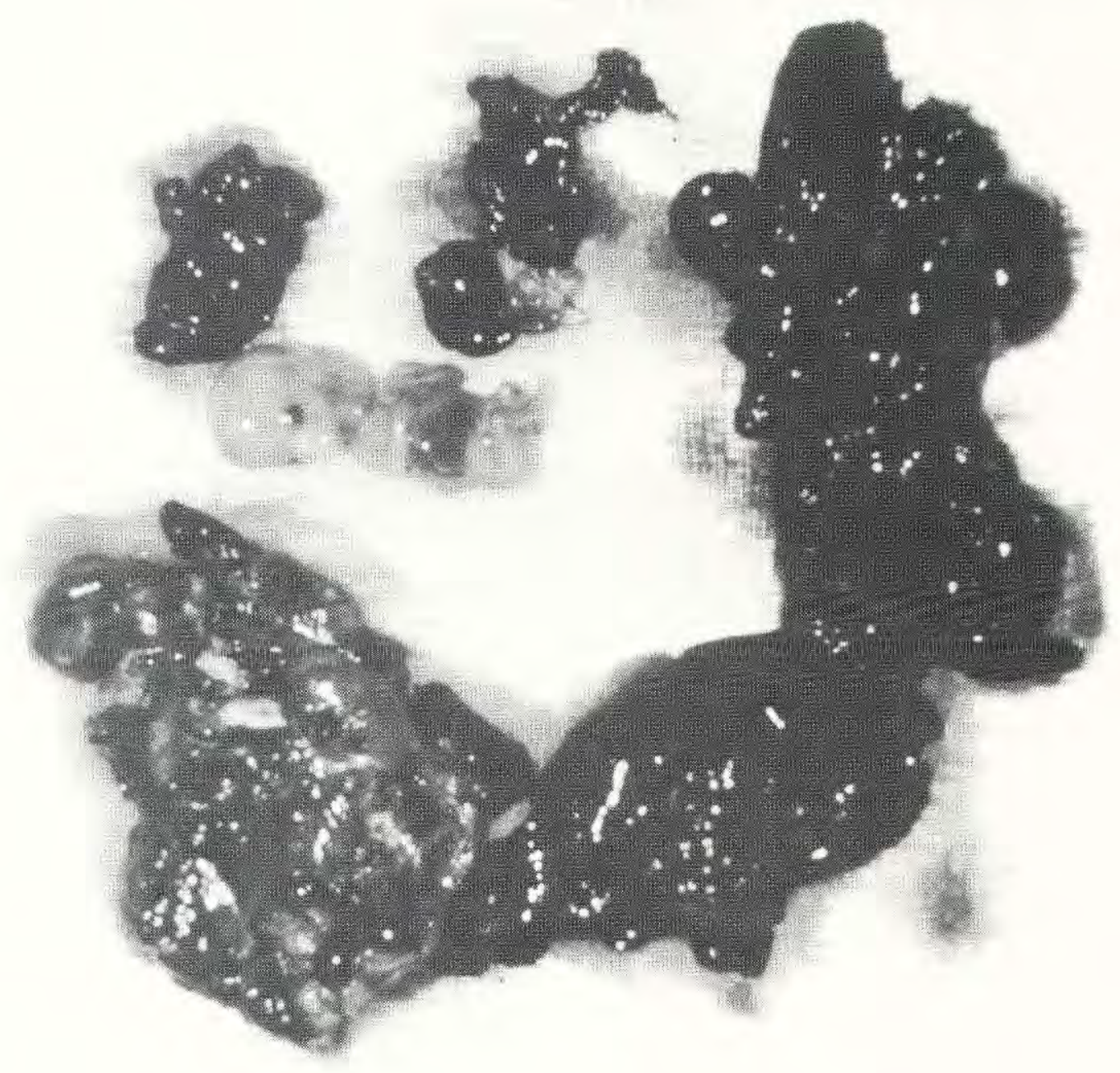

Fig 1. - Foetus and associated haemorrhagic material 
incidence of abdominal pregnancy is variably recorded with marked geographical differences, occurring most frequently in tropical countries ${ }^{4}$. There are series recording incidences varying between 1:26000 deliveries $^{5}$ and 1:6294. . Paes quotes 1:4000 in East Africa; one of the highest incidences recorded.

This tropical bias is thought to be due to the high incidence of pelvic infections in the tropics ${ }^{4}$. The majority of abdominal pregnancies are secondary to tubal rupture or tubal abortion and relating the incidence to ectopic pregnancies would appear to be more appropriate . This incidence varies from 1.5\%-5\% of all ectopic pregnancies. In most cases the extrauterine foetus dies early with very few reaching an advanced gestation ${ }^{4}$. The possible outcomes are illustrated below. (Table 1).

\section{Table 1}

Fate of Abdominal Pregnancy

1. Survival of the child by operative delivery.

2. Death of the child.

3. Maceration.

4. Suppuration.

5. Mummification.

6. Calcification of the fetus.

\section{Lindtjorn \& Lende 1981}

This case illustrates one consistent finding in the history - that of an acute episode of lower abdominal pain with or without bleeding which settles and seemingly allows the pregnancy to continue. Ultrasonic examination of the pelvis at this time could well have shown the extrauterine pregnancy and surgery could have been undertaken then.

In the absence of a further episode of extrauterine bleeding, placentation may become established with the development of a viable fetus. Clinical examination may delineate the sac from a separate small uterus but it would be more likely nowadays that this problem would be identified with the routine use of ultrasound at first booking. Later the foetal parts are usually much more easily felt, malpresentations may occur and a consistently non-engaged presenting part will be found. In the series described by Delte et $\mathrm{al}^{8}$ the cervix remained closed and uneffaced in every case. If the foetus had died then pregnancy-related signs may not be obvious and misdiagnosis of the abdominal mass is not uncommon. Dasadhikary describes such a case admitted under the physicians as a case of splenomegaly ${ }^{9}$.

In the case described, as for any suspected ectopic pregnancy, laparotomy was mandatory. Had there not been a palpable pelvic mass this would have been preceded by laparoscopy. The diagnosis may however not be made until labour when one of the most helpful clinical clues is the absence of palpable uterine contraction.

In view of the maternal mortality rate of $2-18 \%{ }^{10}$ mostly due to intra-peritoneal haemorrhage it is recommended that immediate planned surgery is the proper management ${ }^{8,10}$.

Management of the placenta at laparotomy is the thorniest problem. Naronne ${ }^{2}$ suggests that particular attention should be paid to the location and accessibility of the blood supply, and if accessible and not adherent to a vital organ or major blood vessel then the placenta may be removed.

If this is not possible, which is usually the case, it should be left behind although this makes the postoperative period stormy and increases the morbidity ${ }^{\prime \prime}$. Trophoblastic activity may be monitored with human chorionic gonadotrophin assay. Amethopterin has been shown to reduce placental mass significantly and produce clinical improvement in the patient ${ }^{12.13}$.

In the case of a dead, macerated or necrotic fetus, laparotomy and removal of necrotic fetal tissue and bones should be performed under antibiotic cover ${ }^{4}$.

\section{Acknowledgement}

I should like to thank Brigadier M. B. A. Jackson FRCOG L/RAMC for his permission to publish this case and Mrs G. Shepherd for typing the manuscript.

\section{REFERENCES:}

1 Longo L D. Classic Pages in Obstetrics and Gynaecology. A case of an extra-uterine foetus by John Bard from Medical Observations \& Enquiries (London) Vol 2 pp 369-372 1764. Am J Obstet Gynecol 1975; 123: (3) 305 .

2 Naronne R K et al. Advanced Abdominal Pregnancy. Med.J. Zambia 1980/81; 15: (1) 2-5.

3 Kellett R J. Primary Abdominal (Peritoneal) Pregnancy J Obst Gynae Br Commw. 1973; 80: $1102-1105$

4 Lindtjorn B and Lende S., Abdominal Pregnancy: A Case Report, Ethiop Med J 1981; 19:25-27.

5 Khanam W and Suan A. Abdominal Pregnancy J Obstet Gynaecol India 1976: 26: 771-773.

6 Ramirex C A T et al. Embarazo abdominal Revision de 20 cases. Ginecol Obstet Mex 1981; 49: (292) 89-99.

7 PaEs E H J. Advanced Abdominal Pregnancy: Case Report with a review of the recent literature. East Afr Med J1981; 58: (2) 142-7.

8 DeLte I et al. Abdominal Pregnancy: Review of Current Management and Addition of 10 Cases. Obstet Gynecol 1982; 60: (2) 200-204.

9 DASADHIKARY C R et al. Unusual Presentation of an Abdominal Pregnancy. JIMA 1979; 73: (5, 6) 97-98.

10 StRAFFord J $\mathrm{C}$ and Ragan W D. Abdominal Pregnancy - Review of the Current Management Obstet Gynecol 1977; 50: 548 .

11 QuANE M B. Conservative Management of Extra Uterine Pregnancy. Can J Surg 1976; 19: (4) 359-61.

12 HreshChyrshyn M M et al. Amethopterin in Abdominal Pregnancy. Am J Obstet Gynecol 1965; 93: 286.

13 Bendvold E and RaAbe N. Abdominal Pregnancy. A Case Report and brief revicw of the literature. Acta Obstet Gynecol Scand 1983; 62: 377-379. 